\title{
Battery powered high output voltage bidirectional flyback converter for cylindrical DEAP actuator
}

Huang, Lina; Thummala, Prasanth; Zhang, Zhe; Andersen, Michael A. E.

Published in:

Proceedings of the International Power Modulator Symposium and High Voltage Workshop

Link to article, DOI:

10.1109/IPMHVC.2012.6518778

Publication date:

2012

Link back to DTU Orbit

Citation (APA):

Huang, L., Thummala, P., Zhang, Z., \& Andersen, M. A. E. (2012). Battery powered high output voltage bidirectional flyback converter for cylindrical DEAP actuator. In Proceedings of the International Power Modulator Symposium and High Voltage Workshop IEEE. https://doi.org/10.1109/IPMHVC.2012.6518778

\section{General rights}

Copyright and moral rights for the publications made accessible in the public portal are retained by the authors and/or other copyright owners and it is a condition of accessing publications that users recognise and abide by the legal requirements associated with these rights.

- Users may download and print one copy of any publication from the public portal for the purpose of private study or research.

- You may not further distribute the material or use it for any profit-making activity or commercial gain

- You may freely distribute the URL identifying the publication in the public portal 


\title{
Battery Powered High Output Voltage Bidirectional Flyback Converter for Cylindrical DEAP Actuator
}

\author{
Lina Huang, Prasanth Thummala, Zhe Zhang, Michael A. E. Andersen \\ huang@elektro.dtu.dk, pthu@elektro.dtu.dk, zz@elektro.dtu.dk, ma@elektro.dtu.dk \\ Technical University of Denmark, Department of Electrical Engineering, DK-2800 Kgs. Lyngby, Denmark
}

\begin{abstract}
DEAP (Dielectric Electro Active Polymer) actuator is essentially a capacitive load and can be applied in various actuation occasions. However, high voltage is needed to actuate it. In this paper, a high voltage bidirectional flyback converter with low input voltage is presented. The fundamental operating principle for both energy transfer process and energy recovery process is analyzed in detail. In order to verify the analysis, critical simulation results are provided. So far, a unidirectional flyback converter, which can realize the energy transfer process, has been implemented in the lab. The design parameters for flyback transformer and snubber circuits are illustrated. Moreover, the experimental waveforms are provided.

Index Terms - DEAP actuator, high voltage, flyback, bidirectional
\end{abstract}

\section{INTRODUCTION}

DEAP (Dielectric Electro Active Polymer) is a new type of polymer material, which consists of a soft silicone polymer, sandwiched between two compliant metallic electrodes [1]. The similar structure to a capacitor enables DEAP to be fundamentally considered as a capacitive load. Figure 1 shows the measured impedance of DEAP material at low frequency. The -90 degrees phase an angle can sufficiently illustrate the capacitive property of DEAP.

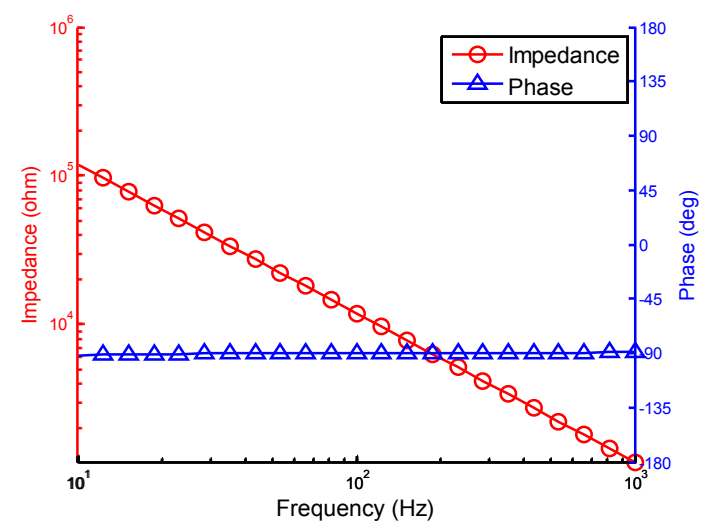

Figure 1. Impedance measurement of DEAP material

When a voltage is applied to DEAP material, the polymer will compress in thickness and expand in area due to the electric field [2]; therefore, DEAP can be used as an actuator. Compared to traditional electro-magnetic, pneumatic or hydraulic actuators, capacitive actuator possesses many advantages, such as high power density, low weight, fast and direct actuation, high actuating precision, extremely low steady-state power consumption, low noise, etc.

Because of the simple design and immense applicable occasions, cylindrical DEAP actuator, which only performs linear motion, will be an effective replacement for many conventional actuators. Figure 2 shows a cylindrical DEAP actuator [3].

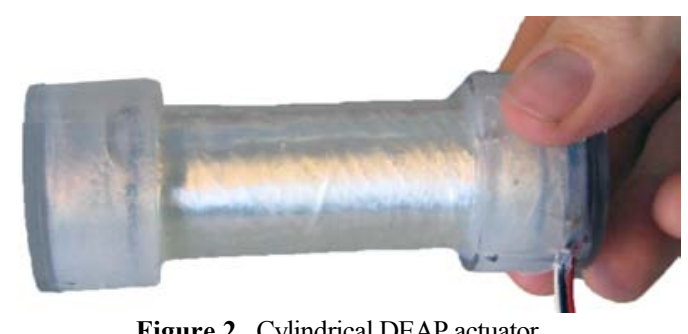

Figure 2. Cylindrical DEAP actuator

The stroke-voltage response of cylindrical DEAP actuator shown in Figure 2, is demonstrated in Figure 3 [4]. It is obvious that DEAP actuator needs high voltage to be fully elongated.

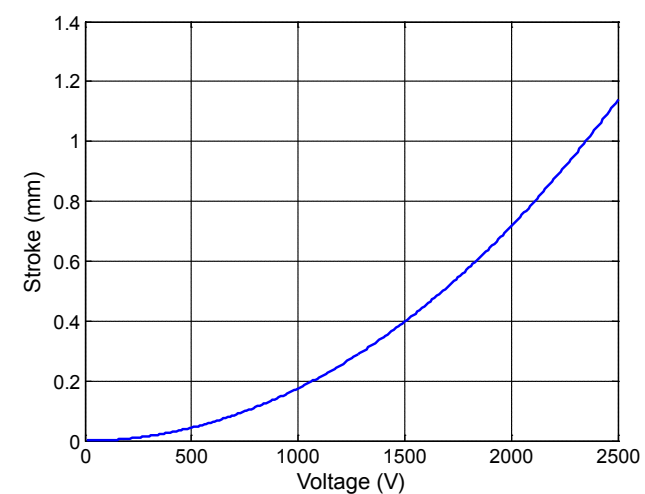

Figure 3. Stroke-voltage characteristic of cylindrical DEAP actuator

Owing to the low weight of DEAP actuator, it can be used in the portable or autonomous systems, where the battery will be the only power source. Therefore, for stimulating DEAP, a DC-DC converter which can convert low input voltage to high output voltage will be necessary. Combined with the capacitive property 
of DEAP material and the objective to extend the lifetime of battery, a bidirectional flyback converter can be a good choice, which can not only boost the low voltage to several thousand volts, but also can recover the stored electrical energy when DEAP actuator is released. Furthermore, due to the simple topology of flyback, the converter can be realized in small size, which is vital in the portable or autonomous applications.

This paper analyzes the working principle of bidirectional flyback converter to drive cylindrical DEAP actuator and validates the feasibility through simulation in Section 2. Until now, only the unidirectional flyback converter was realized in the lab, which can boost the output voltage to $2.5 \mathrm{kV}$ from a $3 \mathrm{~V}$ battery and will be addressed in Section 3. And conclusion is drawn in Section 4.

\section{BIDIRECTIONAL FLYBACK ANALYSIS}

For DEAP actuator, only a small portion of stored electrical energy is converted into mechanical response [5]; therefore, it can approximately be considered as a pure capacitor load in order to simplify the analysis.

\subsection{TOPOLOGY AND WORKING PRINCIPLE}

The bidirectional flyback converter is shown in Figure 4, consisting of coupled inductors in the middle and active power switches in both primary and secondary side.

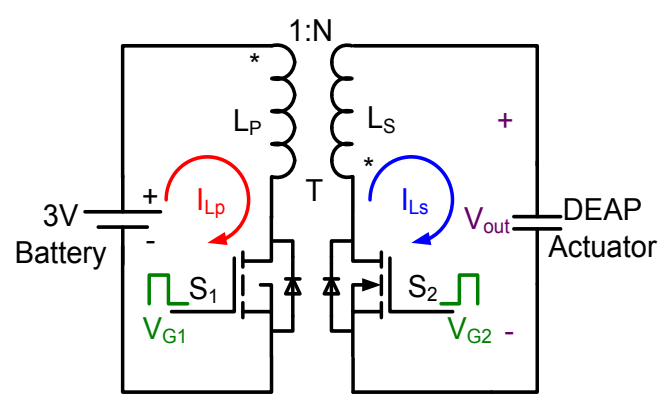

Figure 4. The topology of bidirectional flyback converter

\section{a) Energy transfer process analysis}

When driving DEAP actuator, the electrical energy is transferred to capacitive load from battery. Actually, the energy transfer process includes a series of switching cycles. For each cycle, the primary inductor $L_{P}$ is magnetized in the on-time of $S_{1}$ to accumulate magnetic energy. Then in the offtime of $S_{1}$, through body diode of $S_{2}$, the stored energy will be transferred to DEAP actuator from coupled secondary inductor $L_{S}$. Ideally, the magnetic energy of $L_{S}$ is totally transformed into electrical energy in the capacitive actuator. Moreover, based on the basic principle of LC resonant circuit, in every off-time of $\mathrm{S}_{1}$, inductor current of $L_{S}$ and output voltage $\mathrm{V}_{\text {out }}$ can be expressed in (1) and (2), respectively.

$$
\begin{aligned}
i_{L_{S}}(t) & =i_{L_{S}}(0) \cdot \cos \left(\frac{t}{\sqrt{L_{S} \cdot C_{D E A P}}}\right) \\
& -V_{\text {out }}(0) \cdot \sqrt{\frac{C_{D E A P}}{L_{S}}} \cdot \sin \left(\frac{t}{\sqrt{L_{S} \cdot C_{D E A P}}}\right)
\end{aligned}
$$

$$
\begin{aligned}
V_{\text {out }}(t) & =V_{\text {out }}(0) \cdot \cos \left(\frac{t}{\sqrt{L_{S} \cdot C_{D E A P}}}\right) \\
& +i_{L_{S}}(0) \cdot \sqrt{\frac{L_{S}}{C_{D E A P}}} \cdot \sin \left(\frac{t}{\sqrt{L_{S} \cdot C_{D E A P}}}\right)
\end{aligned}
$$

where $L_{S}$ is the inductance of secondary coupled inductor, $C_{D E A P}$ is the capacitance of DEAP actuator, and $i_{L s}(0), V_{\text {out }}(0)$ are the initial current and voltage for inductor and actuator, respectively.

In order to reduce the charge time of fully elongating DEAP actuator and completely transfer the energy stored in the flyback transformer in each cycle, a boundary mode control strategy can be used [6]. When the current through the body diode of $\mathrm{S}_{2}$ accomplishes freewheeling in the previous cycle, the next cycle immediately starts. In addition, primary peak current control is employed to guarantee the sufficient utilization of magnetic core as well as to avoid its saturation. The fixed input voltage from battery and the application of peak current control make primary conduction time a constant value. However, with the increasing of output voltage, the freewheeling time in secondary side will decrease. That means the switching frequency is variable, and in the early stage of charge, the converter operates in low frequency, whereas at the end, the working frequency becomes high. Although the unfixed operating frequency accelerates the charging process, it also brings some challenges in designing the transformer and analyzing the power loss. The waveforms of first several cycles in charging process are shown in Figure 5.

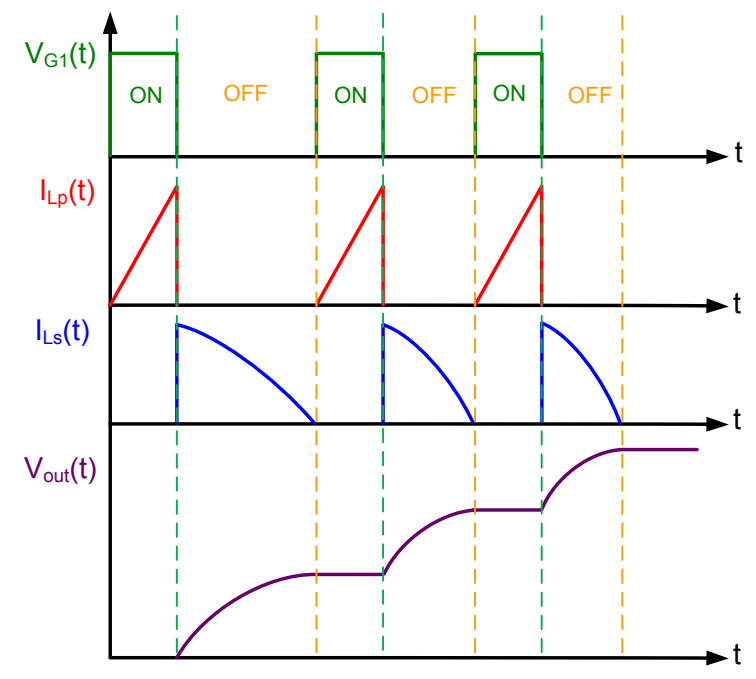

Figure 5. Waveforms in the energy transfer process

\section{b) Energy recovery process analysis}

For the purpose of increasing the service life of battery, it is pivotal to recover the energy stored in DEAP actuator when it is released. Like the charge process, the energy recovery process also consists of many successive switching cycles. Only $\mathrm{S}_{2}$ and the body diode of $\mathrm{S}_{1}$ work in the discharging process. In each cycle, $L_{S}$ obtains magnetic energy from DEAP actuator in the on-time of $\mathrm{S}_{2}$ and releases the stored energy to primary side in the off-time of $\mathrm{S}_{2}$. 
Similar to energy transfer stage, boundary mode control scheme and secondary peak current control are also adopted in discharge process. The waveforms of first several cycles in the energy recovery process are shown in Figure 6.

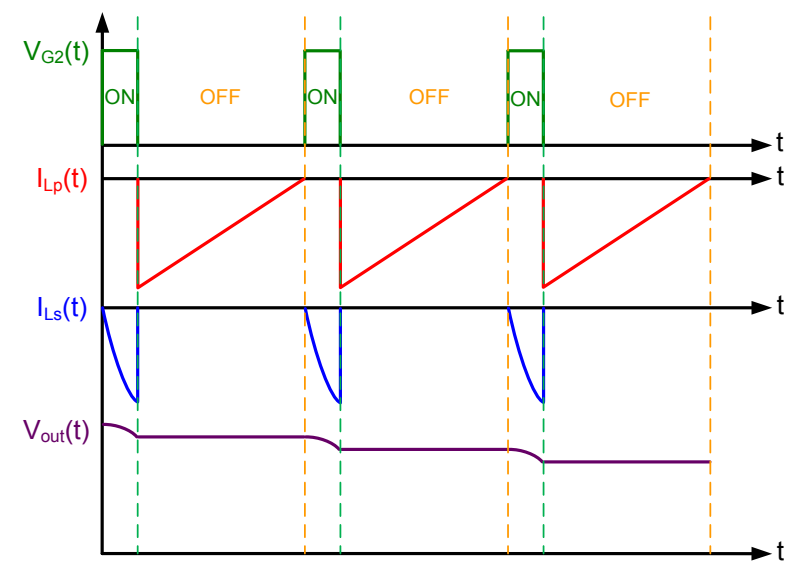

Figure 6. Waveforms in energy recovery process

\subsection{SIMULATION VERIFICATION}

For validating the analysis mentioned above, a bidirectional flyback converter simulation model has been established with PLECS. In addition, a boundary operation mode and peak current control module is also built up. The detailed simulations parameters are shown in Table 1.

Table 1. Simulation parameters for bidirectional flyback converter

\begin{tabular}{c|c}
\hline Simulation Parameters & Values \\
\hline $\mathrm{L}_{\mathrm{P}}$ & $9 \mu \mathrm{H}$ \\
\hline $\mathrm{L}_{\mathrm{S}}$ & $21.36 \mathrm{mH}$ \\
\hline Capacitance of DEAP actuator & $142 \mathrm{nF}$ \\
\hline Vin & $3 \mathrm{~V}$ \\
\hline Primary peak current & $3.9 \mathrm{~A}$ \\
\hline Secondary peak current & $80 \mathrm{~mA}$ \\
\hline $\mathrm{N}$ & 48.7
\end{tabular}

a) Energy transfer process simulation

Figure 7 shows the whole charge process, in which the output voltage increases from 0 to $2.5 \mathrm{kV}$.

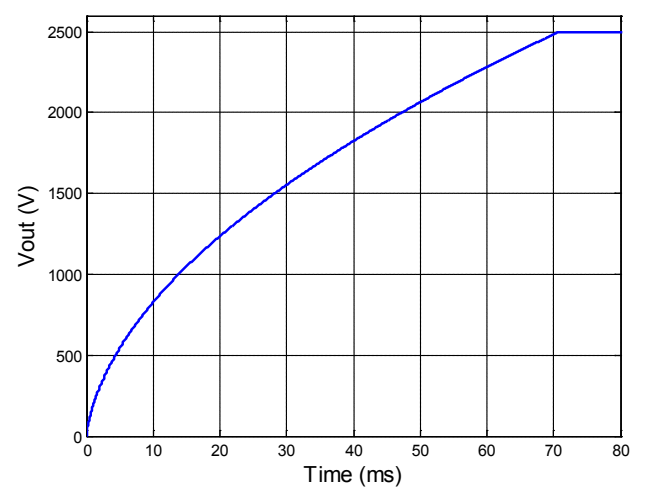

Figure 7. Simulated output voltage waveform in the energy transfer process
In the first several cycles, the current waveforms for both primary and secondary side are shown in Figure 8, which indicates that the boundary mode operation is achieved. Owing to the employment of boundary mode, the charge time is short, only less than $80 \mathrm{~ms}$.

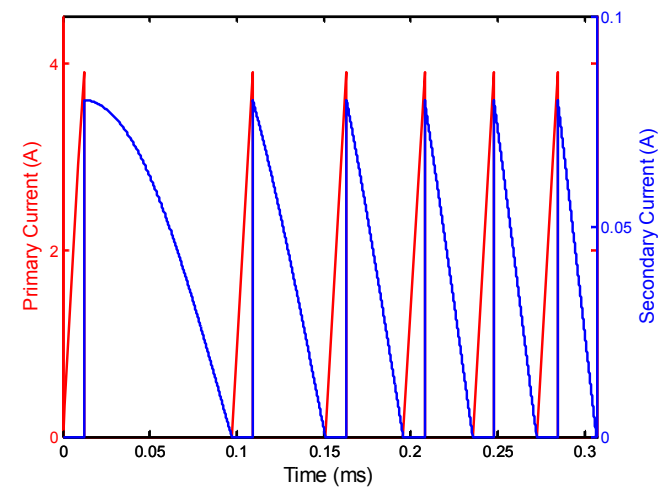

Figure 8. Simulated current waveform in the energy transfer process

\section{b) Energy recovery process simulation}

The output voltage decreases from $2.5 \mathrm{kV}$ to 0 in the energy recovery process, shown in Figure 9. And the current waveforms are provided in Figure 10, which also demonstrates the realization of boundary mode in discharge process.

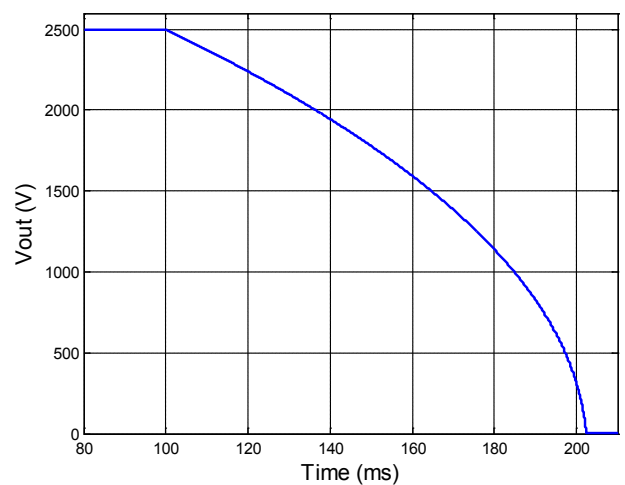

Figure 9. Simulated output voltage waveform in the energy recovery process

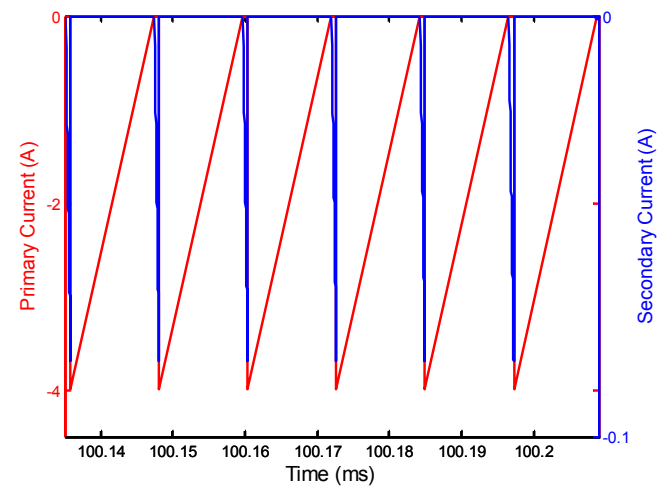

Figure 10. Simulated current waveform in the energy recovery process

\section{UNIDIRECTIONAL FLYBACK DESIGN} AND REALIZATION 
A unidirectional flyback converter to drive DEAP actuator, shown in Figure 11, has been realized in the lab. Because of the voltage stress issue of $\mathrm{S}_{1}$, a RC snubber and a RCD clamp circuits are employed [7].

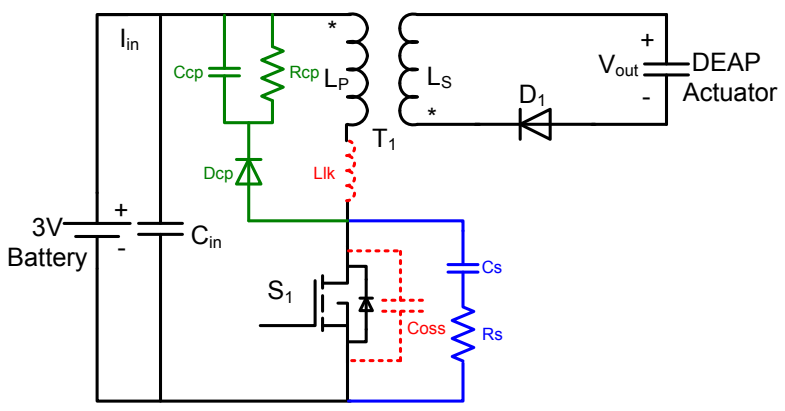

Figure 11. Unidirectional flyback converter

\subsection{DESIGN PARAMETERS}

The detailed design parameters are shown in Table 2, including the parameters of transformer, RC and RCD circuit.

Table 2. Design parameters for unidirectional flyback converter

\begin{tabular}{c|c}
\hline Parameters & Values \\
\hline Turns ratio (primary turns : secondary turns) & $7: 341$ \\
\hline Core type (Core material) & EF20 (N67) \\
\hline Air gap length & $250 \mu \mathrm{m}$ \\
\hline Lp & $9 \mu \mathrm{H}$ \\
\hline Ls & $21.36 \mathrm{mH}$ \\
\hline Leakage inductance $\mathrm{L}_{\mathrm{lk}}$ & $750 \mathrm{nH}$ \\
\hline Capacitance of DEAP actuator & $142 \mathrm{nF}$ \\
\hline Rs of RC snubber circuit & $68.1 \Omega$ \\
\hline Cs of RC snubber circuit & $220 \mathrm{pF}$ \\
\hline Rcp of RCD clamp circuit & $20 \mathrm{k} \Omega$ \\
\hline Ccp of RCD clamp circuit & $1 \mu \mathrm{F}$ \\
\hline
\end{tabular}

\subsection{EXPERIMENTAL WAVEFORMS}

The experimental waveforms are shown in Figure 12, Figure 13 and Figure 14. From Figure 12, it is clear to see the variable switching frequency which is caused by the boundary mode operation.

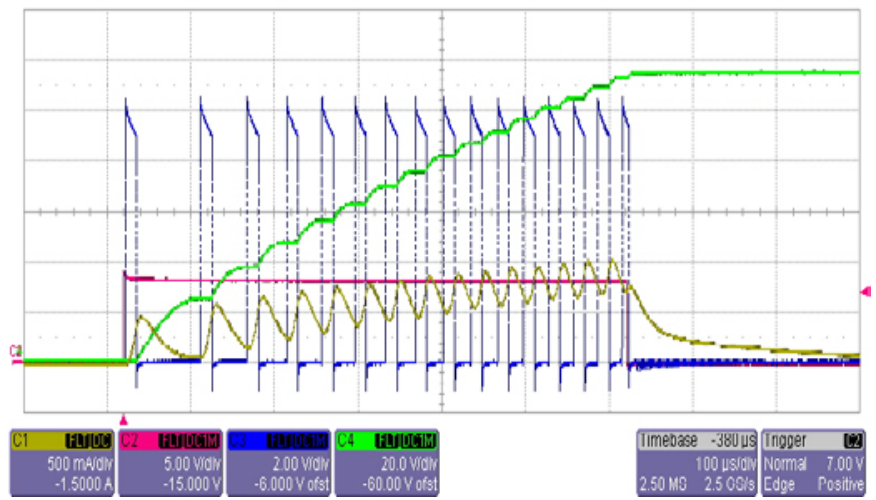

Figure 12. Experimental waveforms $\left(\mathrm{CH} 1\right.$-input current $\mathrm{I}_{\mathrm{in} ;} \mathrm{CH} 2$-charge control signal for converter; $\mathrm{CH} 3$-gate signal of $\mathrm{S}_{1}$; $\mathrm{CH} 4$-output voltage)
The peak current control can be validated in Figure 13 and the whole energy transfer process is shown in Figure 14.

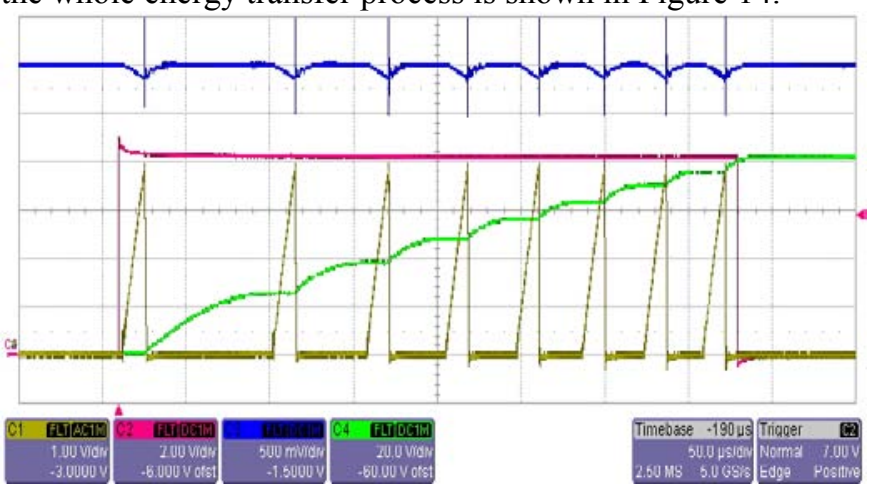

Figure 13. Experimental waveforms ( $\mathrm{CH} 1$-primary winding current; $\mathrm{CH} 2$-charge control signal for converter; $\mathrm{CH} 3$-input voltage; $\mathrm{CH} 4$-output voltage)

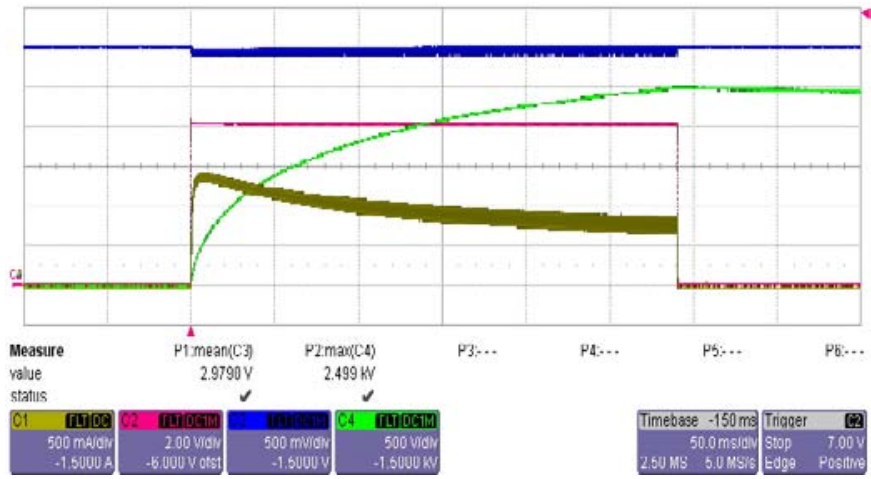

Figure 14. Experimental waveforms $\left(\mathrm{CH} 1\right.$-input current $\mathrm{I}_{\mathrm{in}}$; $\mathrm{CH} 2$-charge control signal for converter; $\mathrm{CH} 3$-input voltage; $\mathrm{CH} 4$-output voltage)

\section{CONCLUSION}

A high voltage bidirectional flyback converter driving DEAP actuator is presented. The detailed analysis for both the energy transfer and the recovery process is discussed. The simulation results are provided to support analysis. In addition, a unidirectional flyback prototype has been implemented in the lab, which can charge DEAP actuator to $2.5 \mathrm{kV}$.

\section{REFERENCES}

[1] M. Y. Benslimane, H. E. Kiil and M. J. Tryson, "Electro-mechanical properties of novel large strain PolyPower film and laminate components for DEAP actuator and sensor applications”, Proceedings of SPIE, Vol. 7642, 2010

[2] M. Y. Benslimane, H. E. Kiil and M. J. Tryson, "Dielectric electroactive polymer push actuators: performance and challenges", Polymer International, Vol. 59, No. 3, pp. 415-421, 2010.

[3] T. Andersen, M. S. Rødgaard, O. C. Thomsen and M. A. E. Andersen "Low voltage driven dielectric electro active polymer actuator with integrated piezoelectric transformer based driver", Proceedings of SPIE, Vol. 7976, 2011.

[4] R. Sarban, R. W. Jones, B. R. Mace and E. Rustighi, "A tubular dielectric elastomer actuator: Fabrication, characterization and active vibration isolation", Mechanical Systems and Signal Processing, Vol.25 No. 8. , pp. 2879-2891, 2011.

[5] M. J. Tryson, R. Sarban, K. P. Lorenzen, "The dynamic properties of tubular DEAP actuators", Proceedings of SPIE, Vol. 7642, 2010.

[6] “LT3750 Capacitor Charger Controller Datasheet”, Linear Technology Corporation, USA.

[7] "Application Note AN-4147 Design Guidelines for RCD Snubber of Flyback Converters", Fairchild Semiconductor Corporation, USA, 2006. 